E3S Web of Conferences 2, 02002 (2014)

DOI: $10.1051 / \mathrm{e} 3$ sconf/ 20140202002

(C) Owned by the authors, published by EDP Sciences, 2014

\title{
The Physics laws and the unsustainability of economic liberalism
}

\author{
Beniamino Ginatempo \\ Dept. Ingegneria Civile, Edile Ambientale e Matematica Applicata, University of Messina, Italy
}

\begin{abstract}
Nature or Physics laws rule everything occurs within the Universe and on the Earth, including economical activities and social processes. Opposite to human laws, Physics laws cannot be transgressed, therefore environmental and economic sustainability can be pursued only through economy development models coherent with them, and it is insanity to think that politics and economy can preferentially respect free market laws.

The first and the second Thermodynamics principles have a great economic and social relevance, because they imply that all human activities are transformations (nothing is created, nothing is destroyed, everything is transformed) with efficiency less than $100 \%$, whose scrap is directly related to the environment pollution. This holds for economical activities too. In fact companies, in order to produce, need raw materials and energy, make wastes and run into debt; consumers, in order to consume, need energy, make wastes and run into debt; governments, in order to provide infrastructures and services for production and consumptions, need energy, make wastes and run into debt. The inputs of such process are then the planet resources while the outputs are debt and wastes that, in turn, require more energy and other resources to be treated. Because of the narrowness of the natural resources this model might get unstable and lead to the economical crisis and to consumption and degradation of the resources, as striking prescription of Thermodynamics laws.

Any alternative model must realize that, since the pollution is unavoidable, it is wise to pollute as least as possible and as slowly as possible. Again the second Thermodynamics principle, not ideology, states that this is possible only through an ordered, fair and jointly liable access to the common assets, opposite to the predatory access onto which free market is based.
\end{abstract}

\section{Introduction}

Within the Universe and on the Earth only physical phenomena can occur. These are permitted and ruled by the Physics or Nature laws. Notwithstanding the Universe and the Earth are extremely complex physical systems, since they are constituted by an enormous number of components (degrees of freedom), whose interactions are certainly very complicated, often quantitatively unknown and poorly approximated, Physics is a very useful instrument to understand what happens in the real world.

Physics laws are absolutely reliable and could help us to find our way within the complexity of all terrestrial events, although the simultaneous occurrence of a huge number of phenomena greatly 
limits, both for technical and conceptual reasons, their predictive potentialities. In other words, although it cannot predict accurately the future, physics could be used to understand everything happens around us, including social and economic phenomena. Moreover, opposite to penal and civil codes or free market laws, physics laws cannot by any means be transgressed. The purpose of this paper is to argue that physics laws could help us to understand the reasons of the actual devastating economical crisis and to suggest, if any, ways out of it or at least to set some guidelines.

Exactly because whatever happens rigorously complies with Physics laws, it is insanity to think that mankind could organize itself on this planet following socio-economical models that do not take them into account or even are in conflict with them. From this point of view, environmental sustainability would seem definable as the plain coherence with Nature laws. Mass conservation principle and the Thermodynamics principles, as we shall see, point out the irremediable conflict between the actual economic system and Nature laws. Such a conflict originates from the linear structure of the neo-liberal model opposite to the cyclic structure of natural phenomena, and therefore it must be concluded that economic liberalism is not a sustainable model.

\section{Conservation laws and the second principle of Thermodynamics}

Conservation laws state that many physical quantities must conserve at the occurrence of any physical phenomena, from which the famous adage Nothing is created, nothing is destroyed, everything is transformed. For the purposes of my analysis the most relevant physical quantities are the Mass and the Energy. Their absolute overall conservation is established by the Mass conservation principle and by the first Thermodynamics principle[1]. The most direct and impacting consequence on our lives is that any human activity (positively no exception) is a transformation of mass into other mass and energy into other energy (but not mass into energy or vice versa!). This holds also for productions and consumptions, the relevant activities from the economical point of view, that are just transformations of raw materials and transformations of products, respectively.

Unfortunately the efficiency of such transformations (exactly because nothing can be created or destroyed) very rarely or never reaches the $100 \%$. Thus in a given transformation the initially available resources cannot be entirely used, but a part of them becomes unusable and often even downgraded (sometimes for ever). The scrap of these transformations of mass and energy is my definition of environment pollution. The inevitability of such a scrap is a profound consequence of the second principle of Thermodynamics[1]. When the downgraded resources increase, physicists - that like cryptic slang - say that the Entropy increases. Let me illustrate this by an example: the entropic car park.

Suppose we want to make a car park in a given area. We should design and draw the parking bays. We have to leave room enough between the bays rows, because the cars could comfortably get into the bays. Also the bays must be larger than the largest car, in order to allow the passengers to get in and out. Therefore the available area (the initially available resource) can be only partially used by the cars. In other words, even if the room was enough for 100 touching cars, we will be able to draw only, say, 60 parking bays: the efficiency of this transformation is, thus, $60 \%$. Some observations:

i) The initial area, the available resource, is not created or destroyed, but it cannot be entirely used.

ii) The remnant $40 \%$ it is not waste, because we could not do better, and it is simply space resource not usable to park.

iii) Indeed we can have a lot of room waste: it is enough that a scoundrel would park straddling two bays, or park in the driving space or blocking the car park entrance. In such a case the efficiency of the transformation is reduced, certainly a lot if everybody would park chaotically.

iv) On the contrary of iii, if the individual behaviours were coordinated, then the common resources will be best used, say with all the cars plainly parked in their bays. 
v) Notice also that the work of drawing the bays helps to bring order into the car park (a physical system), and without this work there would be wastes.

From the above notes, one understands that uncoordinated and selfish or predatory of the available common resources behaviours, reduce the efficiency of the transformations. On the contrary, the coordinated and jointly liable behaviours of individuals can maximize the use of the resources. This is the way, if not the unique certainly the wisest, to slow down the entropy growth, to avoid resources waste and hence the chaos.

The accumulation of the made unusable resources leads to the physical system internal disorder growth (that is the entropy growth), up to a total decay, the thermal death, unavoidable if the system is isolated. To escape this abhorred event, one must take energy from the system outside and use it to order the inside. This energy transfer is the Work, the only mean we have to escape the break-up. In the case of the car park the work was the bays design and drawing. Then, evidently, the only way we have to produce wealth and welfare - and this is one contact point between Thermodynamics and Social Sciences - is to transform the available resources through the Work and the necessary Knowledge to do it, to do it at the best and to do it minimizing the mass and energy scraps.

A last consideration. If we had an unlimited reservoir of energy - although even in this case we shall not be able to make an infinite work - then we could, duly working, keep ordered and alive all the physical systems, including ourselves. But unfortunately such a reservoir unquestionably does not exist, therefore the entropy increase is unavoidable. It seems wise, then, to let it grow as least as possible and as slowly as possible. This is environmental sustainability, in my opinion. For instance, this is what the human beings usually do, since they cannot avoid to get old, but they try to keep themselves alive and in a good health as long as possible.

\section{The physical reason of economical crisis}

In order to respect conservation laws and to allow life on the Earth, Nature has invented a wonderful trick: the materials cycle. The overwhelming majority of natural cycles consists in the composition of simple chemical elements (atoms) in organic matter - as it occurs in living species - and after in the decomposition of the organic matter into their inorganic elementary components. In such processes nothing gets lost, not even a small hydrogen atom that perhaps parks temporarily in a chemical compound, and after a while gets free and makes itself available for the next compound. This way everything gets recycled, exactly because of the circular structure of the natural phenomena, imposed by the conservation laws: there is no input nor output. Also artificial materials (plastics, glass, steel, papers, etc.), gifts of our wonderful technology to improve the comfort in our lives, should be forced in artificial cycles[2]. Their spontaneous decomposition occurs along a huge time scale, much longer than biological matter ones. Because of these time scale difference, technological products after the use might have a serious polluting impact.

The actual economic system, on the contrary, has a linear structure, and this affects its sustainability. It is based on the Gross Domestic Product (GDP) - the rough measure of the wealth yearly produced by a community - and economic system reaches a stationary equilibrium only when the GDP growth is continuous and unbounded. Of course all this works provided that some crumbs of the economical growth is distributed to everybody, in order to quell social conflicts, that would originate because of an unfair distribution of the wealth. Now, the growth can be achieved by means of productions, consumptions and services. But, oversimplifying, in order to produce companies need raw materials and energy, make wastes and run into debt; consumers, in order to consume, need energy, make wastes and run into debt; the states, in order to provide infrastructures and services 
necessary to both productions and consumptions, need energy, make wastes and run into debt. Thus the input of these processes are the planet resources (as well as the finance loans), while the output is public and private debt and wastes. These, in turn, need energy and other resources to be treated, and that could have a large environmental cost.

Both debt and wastes grow quickly, and more than GDP. Some data for Italy[3]: from 1995 to 2006, before the economical crisis, the Italy GDP per capita has grown of $14.6 \%$ (from $€ 17800$ to $€ 20400$ ), while the wastes per capita have grown of $18.1 \%$ (from 456 to $539 \mathrm{~kg} /$ year). Moreover, the debt increase implies wealth transfer from many people to few finance providers.

This linear structure presents evident criticalities and it is at risk of instability.

1. What happens if the input raw material fluxes slow down or their costs increase too much? Productions go down or the companies run into more debt; products prices go up and consumers cannot afford them or run into more debt; the states must support consumptions and productions through public debt increase. All this until states, consumers and companies will not be able to pay off the debts: the economical crisis. This is also precisely what occurs when raw materials run out. Notice also that the raw materials are controlled by very selected oligarchies (e.g. the oil or mining companies), similarly to those of finance companies.

2. What happens if the state budget goes down for tax evasion, corruption, waste of tax payers money, etc.? Public debt goes up and to honour it the governments must cut off public spending and/or increase taxes for companies and citizens. Then productions, consumptions and services go down: the economical crisis.

3. What happens if there are not enough energy and land resources to deal with the huge amount of industrial and household wastes that such a system produce? Think to the water pollution, the nanoparticles in the air, the dioxins in the soil; think to the fishes eating plastics and mercury, the contamination of agricultural products, the birth deformations around the landfills or incinerators, etc.. There is a physical upper bound to this: if to heal environment pollution costs more than the wealth produced, together with the planet decay we run again into the economical crisis.

4. What happens if high education and research funds are cut? Companies loose competitiveness and necessarily productivity goes down, while industrial wastes go up because of lack of better production designs. Also this fact could lead to the economical crisis.

Item 4 sets also the questions of the research and of what kind of sustainability we may choose. High education and scientific research are fundamental services that the states must deliver, because, as it has been said, through work and knowledge we could improve the quality of life and development. Now, if there was a hypothetical technological progress parallel to GDP growth, one could hypothesize a mitigation of the wastes impact and the environment sack - someone calls it "sustainable development". This is a blunder, in my and others' opinion[4]: to mitigate the impacts means to make the effects less devastating, hence only to get a delay of the final disaster, not to avoid it.

This economic system in order to keep itself on must stimulate us continuously to the wild consumption of the unnecessary, in order to have GDP increase. As a consequence, we attack more and more the planet resources, we pile more and more wastes and debts. Now, if the available resources were unlimited, working and studying more and more, perhaps we might reach some kind of dynamic equilibrium - neglecting the fact that input resources fluxes are delivered in an about monopoly regime, in defiance of free market laws. Unfortunately, however, the natural resources are limited, thus this model based on the infinite but unsustainable GDP growth is destroying the new generations future, because of the resources narrowness, the debt accumulation and the environment pollution. Please notice that this is a striking consequence of the principles of the Thermodynamics. 
At this point, it would be very interesting a compared study of the poverty and pollution indicators but I have not the cultural and technical tools of the economists to perform it. I would not be surprised if along the years, and particularly in the last decades, they had the same trend, because the more resources we waste, the less resources are left for everybody and thus the poverty must increase.

In conclusion the GDP infinite growth is an unrealizable myth, forbidden by the Nature laws. This is why the neo-liberalism is structurally unsustainable and must lead sooner or later to the economical crisis and even to the human species extinction[5]. However the actual unique thought on the crisis, iterated as a jingle by governments, parliaments, political parties, bankers, opinion makers and even unions, is that the recipe to get out of the crisis is the growth, namely to increase a) productivity, b) consumptions, c) public spending cuts. But this recipe can only make the crisis worst, because the growth is the disease (since it accelerates the entropy growth), then it can hardly be the therapy[4].

\section{The alternative: equity and solidarity}

The alternative I conceive is based on the coherence with Nature's laws (in Latin America they called it the buen vivir), that is to try to modify the structure of the economical system from linear to cyclic. First we should recuperate and recycle as many materials as possible from the wastes, for instance following the Paul Connett's Zero Waste Strategy[2]. This is in order to slow down the raw materials attack and to greatly reduce the waste production (asymptotically to zero). This also means to change our occidental lifestyle from the actual one based on the crazy consumption to a much sober one. Moreover, the production and the consumption of those products, that at their end of life cannot be recuperated and its constituents disassembled to make secondary raw materials, should be abolished. However, all that is by no means enough: we need a much more rightful and jointly liable access to the so called Common Assets, as Knowledge, Culture, Beauty, etc., but also and mainly to Mass and Energy, the tangible common assets.

I mentioned above that the control of debt and raw materials, by economic oligarchies is one of the key points. The hoarding and the control of available resources is, obviously, a source of enormous power and it does not allow for a universal, free, equitable and liable use of them. This looks as the analogue of the entropic car park metaphor: if somebody appropriates or depredates the common resources, unavoidably the resources scrap becomes larger and larger. In turn this causes an unjustified increase of the unusable resources and, hence, of the entropy. Thermodynamics then, not ideology, prescribes, when dealing with the common assets, the maximum equity and responsibility towards the future inhabitants of this planet. Only transforming them through Work and Knowledge, maximizing their use and minimizing their scraps, it is possible to produce sustainable wealth and welfare for everybody.

It must be debunked also the "at all costs growth" myth, because only selecting what should increase and what should decrease we could pursue environmental and economical sustainability. However, at this end we need really aware politics and politicians, and today they do not seem equipped nor minded at all to tackle such a hard task. Particularly because this should collide with the interests of economic potentates and should break down their consolidated privileges. In any case, admittedly, it will not be that bad if our governors and the citizens would know a little more of Thermodynamics.

\section{References}

1. B. Ginatempo "Le leggi di Natura e la politica debole", ISBN: 9788891046390 (2013) 
2. P. Connett et al., "Rifiuti zero, una rivoluzione in corso", Dissensi Edizioni, ISBN: 9788896643136 (2012)

3. M. Pagani "I rifiuti fanno da traino al PIL?", url ecoalfabeta.blogosfere.it/2007/05/i-rifiutifanno-da-traino-al-PIL.html (2007); and Hera (2012), L'itinherario invisibile, chap. 4, url: ragazzi.gruppohera.it/binary/hera_ragazzi_2012/risorse_didattiche/Ciclo_Ambiente_cap_4.pdf, and references to ISPRA e CNEL reports therein.

4. See for example S. Latouche "Breve trattato sulla decrescita serena" (2007), Bollati Boringhieri eds., ISBN 9788833918693

5. Extinction of a biological species occurs when it is not able to collect any more energy and other resources from the environment in order to reduce its own entropy. See for example Erwin Schrödinger, "What is Life? The Physical Aspect of the Living Cell", Cambridge, Cambridge University Press (1944) 